\title{
THE INCIDENCE OF SCLEROSIS OF THE CORNU AMMONIS AND CONVULSIONS IN GENERAL PARESIS.*
}

\author{
By A. E. TAFT, Boston, Mass.
}

Since the description by Meynert, in 1893, of sclerosis of the cornu ammonis in epilepsy, this condition has been taken to signify a convulsive tendency.

Anatomically, the cornu ammonis forms a part of the olfactory cortex. In 1867 Voisin called special attention to early anosmia in general paralysis. He considered it of great diagnostic importance, and as a result of his experience concluded that it is almost constant; it is found in no other disease (except local olfactory conditions); it can be identified earlier than tremor of the tongue, inequality of the pupils, or alteration of memory. Mention of this finding has also been made more recently by others, among whom are Dejerine, P. Marie, Ballet and Blocq, and A. Marie. It has been described as partial, complete, unilateral, and Bilateral. Bratz has devoted considerable time to the study of the cornu ammonis with the point of determining its relation to convulsions, and Oppenheim has also discussed the subject. Bratz found sclerosis in 50 per cent of genuine epileptics, and in 20 per cent of general paralytics examined. In the latter he was unable to find a constant history of convulsions, and made no correlation. He failed to find such sclerosis in various other types of mental disease, as acute exhaustive psychoses, alcoholism, apoplexy, tumor cerebri, or mental states in diabetes.

An additional negative report is that of Wakushima, from Obersteiner's laboratory, who examined both cerebral hemispheres from twenty-eight subjects.

Some time ago the writer had the opportunity of examining the brain of an individual who had gone to the hospital with a tentative diagnosis of brain tumour. In the hospital the alternative diagnosis of general paralysis was made. Clinically there were, among other symptoms, convulsions with olfactory aura, and partial loss of olfactory sense. The latter consisted in the inability to differentiate

* The work was made possible through a grant from the United States Interdepartmental Social Hygiene Board, Washington, D.C. From the Department of Neurosyphilis, Boston Psychopathic Hospital, Boston, Massachusetts. 
odours, although there was some perception of general sensory stimulation. Post mortem, the only notable gross finding was a very evident degeneration of the large pyramidal cells of the cornu ammonis on both sides. Microscopically this could be demonstrated as complete cell loss and extreme gliosis.

In examining histologically the brain tissue from a group of cases of general paresis, sections from the cornu ammonis were included in the series, and it became apparent that there was an almost direct parallel between cell loss in this area, and the incidence of convulsions. The disappearance of the large pyramidal cells inside the corpus dentatum was complete, or very nearly so, in all cases, contrasting markedly with the normal picture (see Plate I).

Of the 50 cases studied, 19 (38 per cent) gave histories of convulsive seizures, and of this number, all but one showed loss of the large pyramidal cells of the cornu ammonis; mainly those within the corpus dentatum, but frequently extending in some degree into the pre-subiculum. The areas from which the nerve-cells were absent were in a greater. or less degree infiltrated with large amœboid glia cells, or large astrocytes, indicating the presence of a degenerative process. In the one case which was the single exception, a moderate number of astrocytes were present, although no gross cell loss was. demonstrable. In this instance it may have been that the section examined was not from the level of the gyrus suffering greatest change. No proof of this was attempted.

The question then arose whether in any instance the change in the cornu ammonis existed without the occurrence of convulsions. This condition was found in only one case. The section here differed from the others histologically, however, in that the loss of cells was apparent only outside the corpus dentatum. This would suggest a functional difference between the cells of the cornu ammonis within the granular layer and those without. The nearly direct parallel between the occurrence of convulsions and the histological findings in the cornu ammonis seems more than a suggestion that there is some definite relation between the degeneration of that part of the olfactory cortex represented by the cornu ammonis, and the convulsions of general paresis.

\section{SUMMARY.}

Sclerosis of the cornu ammonis was described by Meynert in 1893, in relation to the convulsions of epilepsy. Anosmia has frequently been observed as an early sign in general paresis.

Of 50 cases of general paresis, examined histologically by the writer, 19 had a history of convulsions.

Of these 19, all but one showed extreme loss of large pyramidal 
INCIDENCE OF SCLEROSIS OF THE CORNU AMMONIS AND CONVULSIONS IN GENERAL PARESIS.

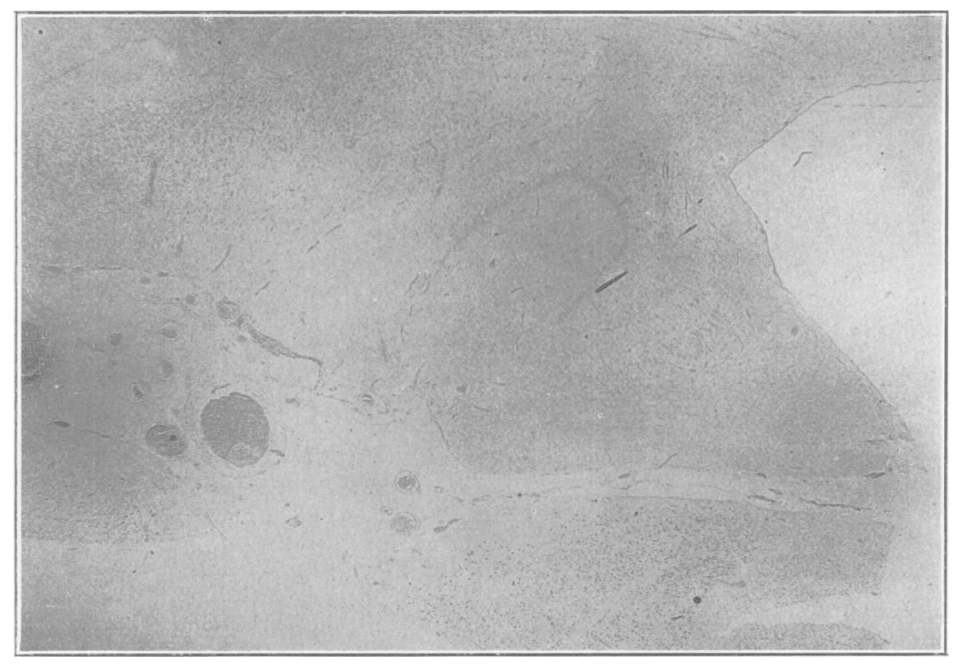

Fig. A.-Cornu ammonis from a case of general paresis with convulsions.

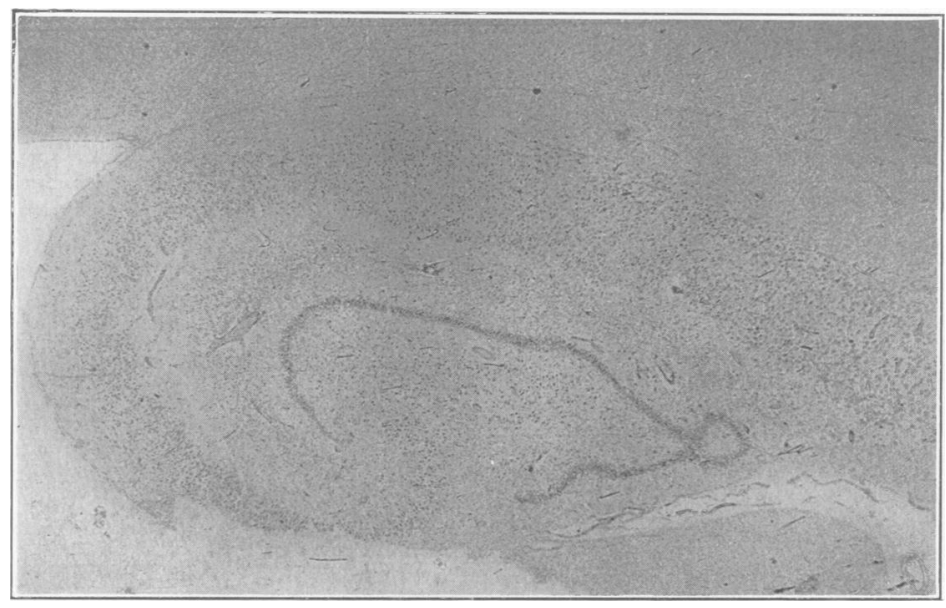

FIG. B.-Cornu ammonis from a case of general paresis without convulsions.

Journal of Neurology and Psychopatholngy, 1921, Vol. II, No. 7. 
cells of the cornu ammonis; particularly those within the corpus dentatum: In some instances the cell degeneration extended into the pre-subiculum. The cell loss was accompanied by proliferation of large glia ceiìs.

In the entire group of cases there was one contrasting case with loss of cells in the cornu ammonis without a history of convulsions. In this instance there was no disappearance of cells within the corpus dentatum ; only from a portion of the pre-subiculum.

Thus, in the histological material examined, there was found an almost exact parallel between the occurrence of convulsions and the presence of marked cell degeneration of the cornu ammonis in 50 cases of general paresis.

\section{BIBLIOGRAPHY.}

Voisin, Traité de la Paralysie générale, 1879.

Dejerine, Sémiologie du Système nerveux, 1126.

MARIe, P., La Pratique neurologique, 147.

BALlet and Bloce (quoted by Dejerine, loc. cit.).

MARIe, A., La Démence, 1906, 81.

Bratz, Monats. f. Psychiat. u. Neurol. 1920, xlvii, 56.

Wakushima, Obersteiner's Arbeiten, 1911-12, 380. 